\title{
The Influence of Environment Temperature on the Degradation of Lead Zirconate Titanate Ceramic
}

\author{
Fei HUANGa, De-Yi ZHENG ${ }^{\text {b, }}$, Shun-Min HU, Gui-Gui PENG \\ Gui Zhou university, Gui Zhou province, China \\ a513577730@qq.com, b24135769@qq.com) \\ *Corresponding author
}

Keywords: Lead Zirconate Titanate (PZT) Ceramic, Degradation, Abnormal Fatigue.

\begin{abstract}
Lead zirconate titanate (PZT) ceramic, as a kind of piezoelectric material, is widely used in the field of electronic industry because of its excellent piezoelectric characteristics and low cost. Research works found that during the working time of the PZT ceramic, an electrical degradation phenomenon will occur that is represented as the decreasing of the electrical resistance and piezoelectric properties and the increasing of leakage current. When increase the temperature of the work environment, the lifetime of the piezoelectric ceramic will be dramatically shorted. This work proposes to analyze the influence of working temperature on the lifetime of piezoelectric ceramic by detecting the changes of leakage current of piezoelectric ceramics under different temperature. The study has important significance on solving the abnormal fatigue aging problem of piezoelectric ceramic in the different working environment.
\end{abstract}

\section{Introduction}

Lead zirconate titanate (PZT) piezoelectric ceramic is with electrical degradation under electric field. The leakage current of sample rises gradually and the resistance reduce. The influence of voltage, temperature and humidness on the degradation of PZT has been studied extensively. For example, E. Loh has considered the grain boundary model to explain the degradation. This theory holds the point that the direct reason of degradation is the crystal boundary's degradation because of the voltage (DC). J. Thongrueng et al proposed another theory of the metal ion's migration to explain the phenomenon of degradation and blackboard. But how the temperature dose influence on the PZT is not reported, this article designs a simple experiment to explain the influence of temperature on the PZT and provide us a method to predict the lifetime of PZT.

\section{Experiment}

This sample's formula is $\mathrm{Pb}(\mathrm{Zr} 52 \mathrm{Ti} 48) \mathrm{O} 3+0.1 \mathrm{wt} \% \mathrm{~K}+0.5 \mathrm{wt} \% \mathrm{Cr}$, which is used in this experiment, and the sample's size is $20 \mathrm{~mm} \times 5 \mathrm{~mm} \times 0.15 \mathrm{~mm}$. In order to get the expectant result, we designed the experiment terrace.

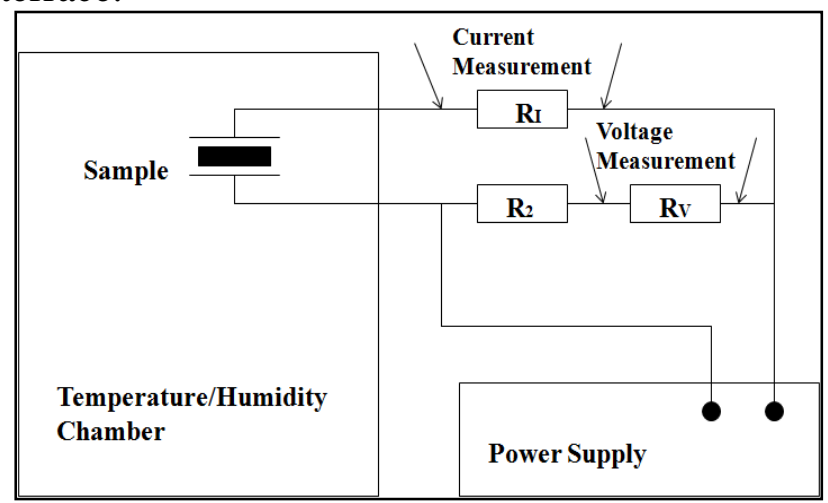

Fig. 1 The experiment terrace 
The figure 1 is the experiment terrace. In the picture, the power supply provides steady voltage $(230 \mathrm{~V})$. Because of the sample's resistance is greater than $10 \mathrm{M} \Omega$, but the series connection resistance is just $10 \mathrm{k} \Omega$, so the voltage of the sample is $230 \mathrm{~V}$ approximate. In the experiment, the surroundings humidness is $90 \% \mathrm{RH}$, and the temperature is $50^{\circ} \mathrm{C}, 60^{\circ} \mathrm{C}$ and $70^{\circ} \mathrm{C}$. We recorded the sample's leakage current and analyzed it as follows.

\section{The Consequence and Analyses}

In order to obtain the effect of the temperature on the electrical degradation of PZT, samples leakage current changing with the time at different temperature, "Samples at different temperature resistance changing with the time ", "Through the sample leakage current reaches a certain value when the relationship between time and temperature" three fact to analysis.

\section{Samples Leakage Current and Resistance Changing with the Time at Different Temperature}

The electrical degradation rate under different environmental conditions of Lead zirconate titanate piezoelectric ceramic samples in different electrical shows as the Fig.2.

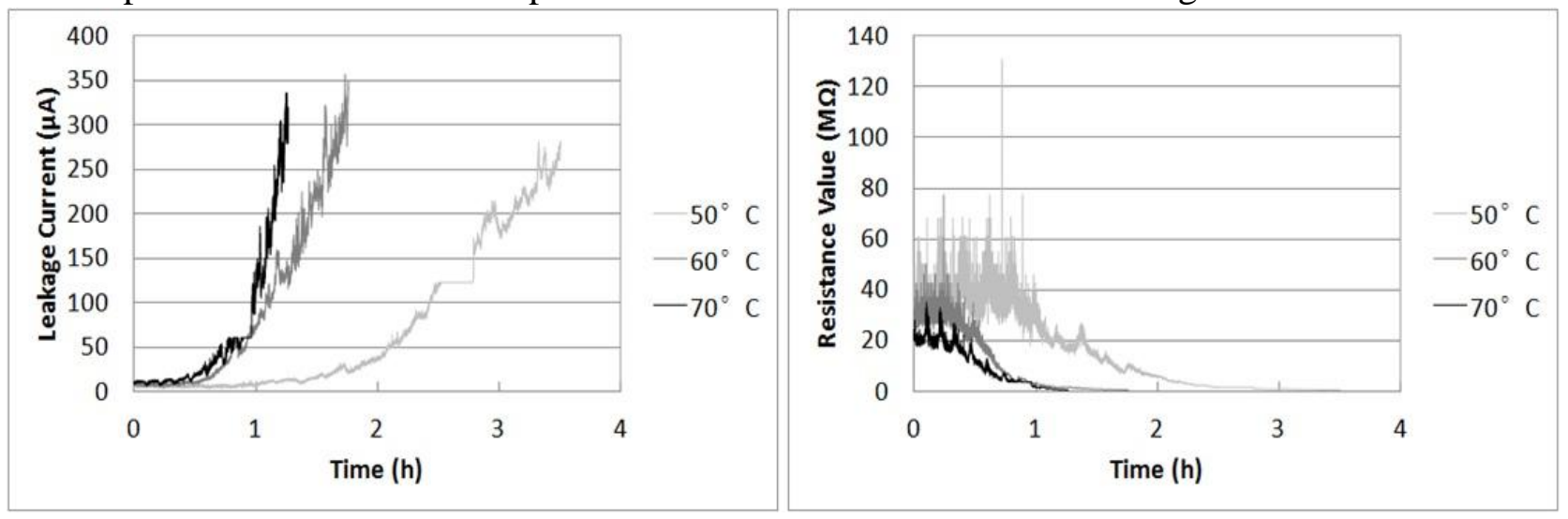

Fig.2 The relationship of resistance and leakage current of samples under different temperature and time

The Fig.2 shows that sample's leakage current and resistance changing with the time at the different temperature $\left(50^{\circ} \mathrm{C}, 60^{\circ} \mathrm{C}, 70^{\circ} \mathrm{C}\right)$ when the humidity is $90 \% \mathrm{RH}$. From Fig. 2 , Through the sample of the leakage current increases with the increase of temperature the speed was accelerated, when the temperature is $70^{\circ} \mathrm{C}$, samples has the fastest electrical degradation rate. Electrical degradation rate of the slowest is under the condition of temperature of $50{ }^{\circ} \mathrm{C}$, but from the fig. 2 , it can be obvious seen that when the temperature is 60 , its electrical degradation rate is not the environment temperature of $50{ }^{\circ} \mathrm{C}$ and $70{ }^{\circ} \mathrm{C}$ under the condition of the average, Samples of the resistance with the temperature rise rate decreases, Reduce the rate increases with temperature, The sample resistance decreases with temperature increase rate was not present a linear trend.

\section{Through the Sample Leakage Current Reaches a Certain Value when the Relationship between Time and Temperature}

Collect the relevant 2 points, using the data analysis, Fitting by the leakage current of the sample at different values of the relationship between time and temperature. Shows in Fig.3.

Fig.3 fitted the leakage current of different values of the relationship between time and temperature. From the Fig.3, it can be seen that no matter what the samples electrical degradation to the leakage current of $150 \mu \mathrm{A}, 200 \mu \mathrm{A}$ or $250 \mu \mathrm{A}$, the time(t) and temperature (T) are fitted below formula:

$$
\mathrm{T}=\alpha \mathrm{t}^{\beta}
$$


The leakage current reaches a certain value, based on the relationship between the time and temperature:

$$
t=\left(\frac{T}{\alpha}\right)^{\frac{1}{\beta}}
$$

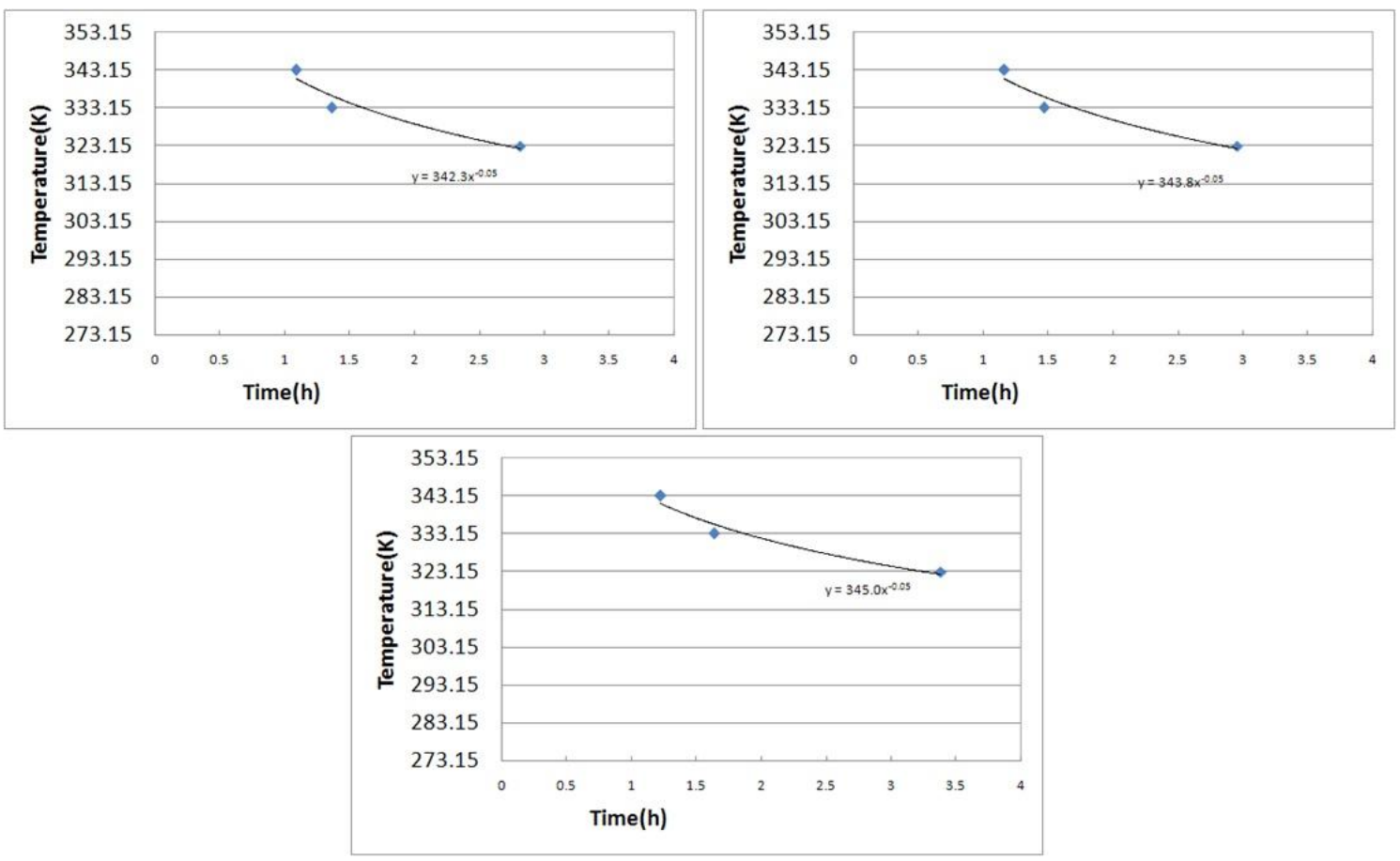

Fig.3 The relationship of time and temperature while the samples electrical degradation up to $150 \mu \mathrm{A}, 200 \mu \mathrm{A}$ and $250 \mu \mathrm{A}$

The $\alpha$ and $\beta$ is constant in the formula, the $\alpha$ rises up gradually from $342.3 \mathrm{~K}$ with the leakage current $(\geq 150 \mu \mathrm{A})$. The $\beta$ equals to -0.05 . We matched the relationship of the $\alpha$ and the leakage current IL in the fig. 4 .

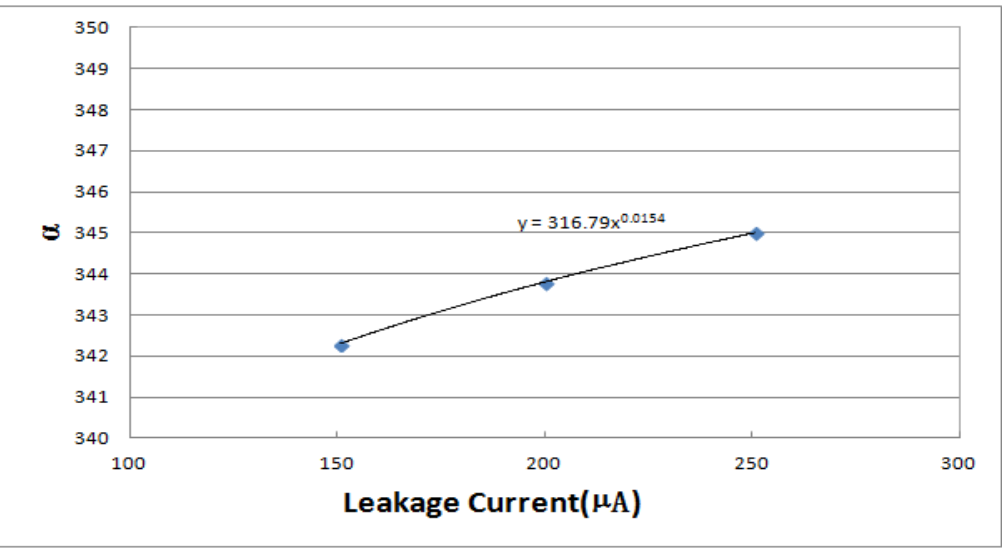

Fig.4 The relationship of the $\alpha$ and IL

In fig.4, we know:

$\alpha=\mathrm{mI}_{\mathrm{L}}{ }^{\mathrm{n}}$

And 


$$
\begin{aligned}
& \mathrm{t}=\left(\frac{\mathrm{T}}{\left.\mathrm{mI}_{\mathrm{L}}\right)^{\frac{1}{\beta}}}=\mathrm{m}^{-\frac{1}{\beta}} \mathrm{T}^{-\frac{1}{\beta}} \mathrm{I}_{\mathrm{L}}{ }^{-\frac{\mathrm{n}}{\beta}}\right. \\
& -\frac{1}{\beta}=\gamma, \mathrm{m}^{-\frac{1}{\beta}}=\mathrm{C}, \quad{ }^{-\frac{\mathrm{n}}{\beta}}={ }^{\delta}, \mathrm{so}: \mathrm{t}=\mathrm{CT}^{Y} \mathrm{I}_{\mathrm{L}}{ }^{8} \quad(\gamma<0, \quad|\gamma|>1)
\end{aligned}
$$

From the formula we can work out that the temperature is higher, the degradation rate is more quick. We can use this formula to compute the lifetime of the PZT while ascertain the leakage current $\mathrm{I}_{\mathrm{L}}$.

\section{Experiment on the Relationship between Different Time Leakage Current and Temperature}

Collect related point in the Fig.5, Fitting the experiment to the different time $(0.25 \mathrm{~h}, 0.5 \mathrm{~h}, 1 \mathrm{~h})$, the relationship between leakage current and temperature through the sample, show as Fig.5.

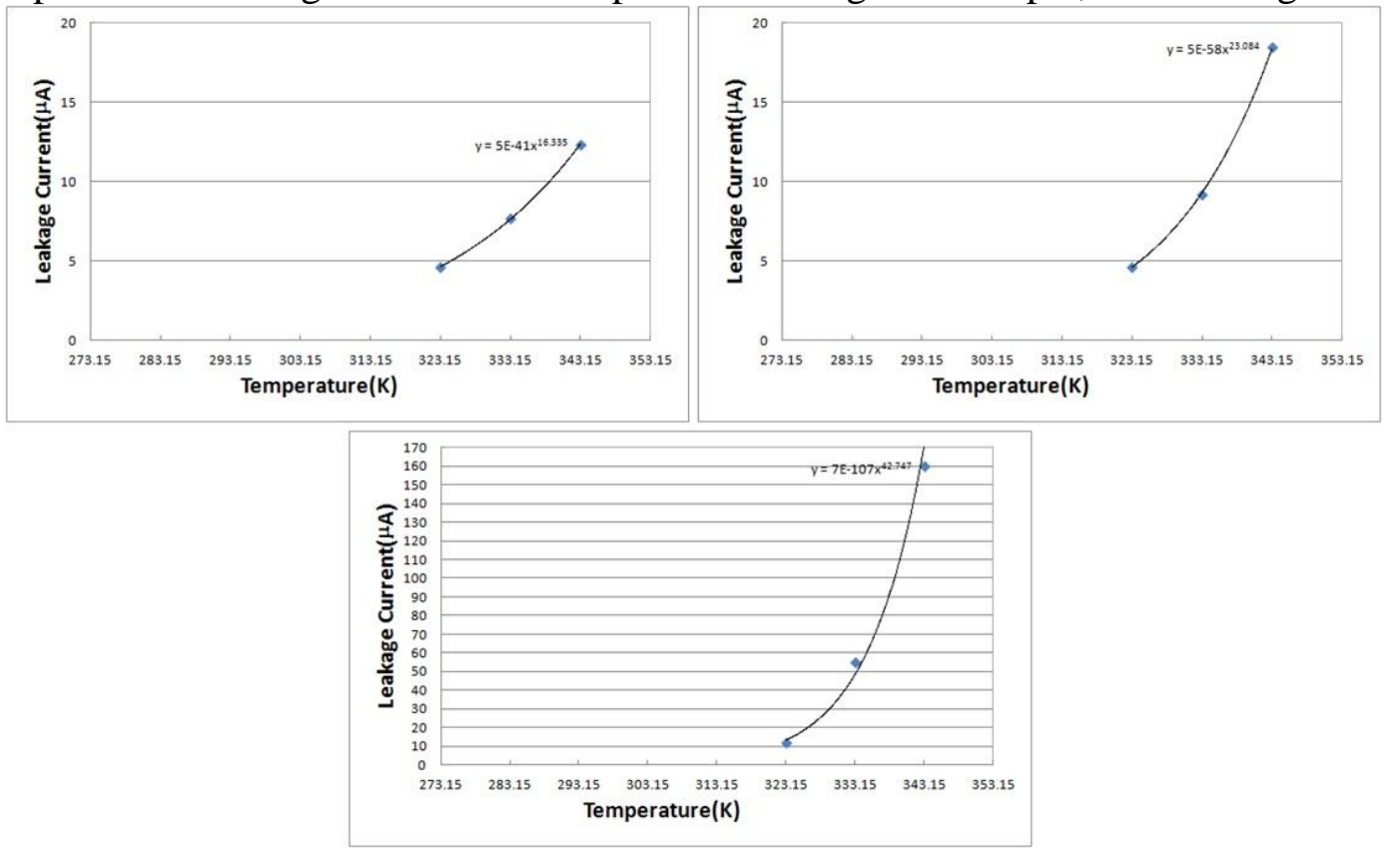

Fig.5 The relationship between leakage current and temperature through the sample when the experiment work times to $0.25 \mathrm{~h}, 0.5 \mathrm{~h}$ and $1 \mathrm{~h}$

From the Fig.5, it can be seen that no matter what the time is $0.25 \mathrm{~h}, 0.5 \mathrm{~h}$ or $1 \mathrm{~h}$, the relationship between leakage current and temperature through the PZT sample satisfy the below formula:

$$
\mathrm{I}_{\mathrm{L}}=\alpha \mathrm{T}^{\beta}
$$

The $\alpha$ and $\beta$ are constant, $\alpha$ order of magnitudes is $10^{-107}-10^{-41}$, the value of $\beta$ is increasing from 16.335, and the increasing rate is corresponding with temperature, along with the temperature increasing, the leakage current of the samples increased similar. In all, the temperature can attribute to the rate of electrical degradation increasing.

\section{Conclusion}

a.The relationship of temperature and the time of the sample's leakage current rising a constant value:

$$
\mathrm{t}=\mathrm{CT}^{\mathrm{Y}} \mathrm{I}_{\mathrm{L}}{ }^{\mathrm{g}}(\gamma<0, \quad|\gamma|>1)
$$


We can use this formula to compute the lifetime of the PZT while ascertain the leakage current $\mathrm{I}_{\mathrm{L}}$.

b. The relationship of leakage current and temperature is:

$$
\mathrm{I}_{\mathrm{L}}=\alpha \mathrm{T}^{\beta}(\beta>1)
$$

\section{Acknowledgment:}

This work was financially supported by the Training Programs of Innovation and Entrepreneurship for postgraduate. The number of the program is 2014085 .

\section{Reference}

[1] D. Zheng, J. Swingler, P. Weaver, The Influence of Electrode Materials on the Electrical Degradation Process of Lead Zirconate Titanate under Harsh Operating Environment, Advanced Materials Research 535-537(2012) 1507-1511.

[2] I. Lipscomb, P. Weaver, J. Swingler, and J. McBride, The effect of relative humidity, temperature and electrical field on leakage currents in piezo-ceramic actuators under dc bias, Sensors and Actuators A: Physical 151 (2009) 179-186.

[3] P. M. Weaver, M. G. Cain, M. Stewart, A. Anson,J. Franks, I. P. Lipscomb, J. W. McBride, D. Zheng, J. Swingler, The Effects of Porosity, Electrode and Barrier Materials on the Conductivity of Piezoelectric Ceramics in High Humidity and DC Electrical Field, Smart Materials \& Structures 21 (2012) 045012. 